\title{
PENGARUH PEMASANGAN KAPASITOR BANK TERHADAP FAKTOR DAYA PADA REEFER PLUG DI PT. PELINDO IV CABANG MAKASSAR NEW PORT
}

\author{
Raya Pasangkunan ${ }^{1}$, Sugeng A Karim ${ }^{2}$, Hasrul ${ }^{3}$ \\ ${ }^{1}$ Pendidikan Teknik Elektro, Universitas Negeri Makassar \\ pasangkunaraya@gmail.com \\ ${ }^{2}$ Pendidikan Teknik Elektro, Universitas Negeri Makassar \\ sugengakarim@gmail.com \\ ${ }^{3}$ Pendidikan Teknik Elektro, Universitas Negeri Makassar \\ hasrulbakri@unm.ac.id
}

\begin{abstract}
ABSTRAK
Penelitian ini adalah penelitian deskriptif yang bertujuan untuk mengetahui pengaruh pemasangan kapasitor bank terhadap faktor daya yang ditinjau dari daya reaktif pada reefer plug. Serta untuk mengetahui pengaruh pemasangan kapasitor bank terhadap faktor daya yang ditinjau dari presentase efisiensi daya pada reefer plug. Objek pada penelitian ini adalah beban listrik pada reefer plug. Teknik pengumpulan data yang digunakan adalah teknik observasi dan dokumentasi. Teknik analisis data yang digunakan adalah teknik analisis statistik deskriptif. Berdasarkan hasil penelitian disimpulkan bahwa rata-rata daya reaktif yang dikompensasi oleh kapasitor bank sebesar 51,6 kVAR, kemudian rata-rata presentase efisiensi daya listrik sebesar $27,04 \%$.
\end{abstract}

Kata Kunci: Kapasitor Bank, Faktor Daya, Reefer Plug.

\section{THE EFFECT OF INSTALLATION OF BANK CAPACITATORS ON POWER FACTORS ON REEFER PLUG AT PT. PELINDO IV MAKASSAR BRANCH NEW PORT}

\begin{abstract}
This research is a descriptive study that aims to determine the effect of installing a capacitor bank on the power factor in terms of reactive power on the reefer plug. And to determine the effect of the installation of a capacitor bank on the power factor in terms of the percentage of power efficiency on the reefer plug. The object of this research is the electrical load on the reefer plug. Data collection techniques used are observation and documentation techniques. The data analysis technique used is descriptive statistical analysis technique. Based on the results of the study, it was concluded that the average reactive power compensated by the capacitor bank was $51.6 \mathrm{kVAR}$, then the average percentage of electric power efficiency was $27.04 \%$.
\end{abstract}

Keyword: Capacitor Bank, Power Factor, Reefer Plug. 


\section{PENDAHULUAN}

Penggunaan energi listrik dalam kapasitas besar pada umumnya digunakan untuk keperluan usaha atau bisnis. Namun, dalam penggunaan listrik berkapasitas besar terkadang menghadapi berbagai macam permasalahan. Permasalahan tersebut antara lain adanya rugi-rugi jaringan dan penurunan tegangan yang terjadi pada saluran [1]. Perkembangan teknologi belakangan ini mengalami kemajuan yang cukup pesat ditandai dengan adanya peralatan-peralatan elektronik atau yang biasa disebut dengan beban listrik. Salah satu permasalahan dalam penyaluran daya listrik ke pusat beban adalah memburuknya faktor daya yang diakibatkan oleh pemakaian beban-beban listrik bersifat induktif [2].

Sektor industri merupakan konsumen PLN yang cukup besar menyerap energi listrik, pada industri umumnya mempunyai beban-beban induktif yang mengandung gulungan-gulungan kawat seperti motor-motor listrik, transformator, dan beban induktif lainnya yang membutuhkan daya aktif dan daya reaktif yang cukup besar. Bertambahnya beban yang bersifat induktif membutuhkan daya reaktif yang sangat besar sehingga sumber (pembangkit listrik) harus mensuplai daya yang lebih besar. Keadaan seperti ini dapat menyebabkan jatuh tegangan, arus pada jaringan bertambah dan faktor daya rendah pada daerah dekat beban [3].

PT. Pelindo IV Cabang Makassar New Port merupakan salah satu badan usaha milik negara yang bergerak pada bidang kepelabuhan. Pengunaan energi listrik sangat dominan sehingga membutuhkan akan kualitas daya listrik yang baik, yang ditunjang dari berbagai peralatan listrik yang digunakan baik dalam kantor operasional, power house, reefer plug dan di dermaga yang menggunakan peralatan-peralatan listrik, maka sangat dibutuhkan kualitas daya listrik yang baik dalam menunjang segala bentuk aktifitas pekerjaan dalam lingkup Makassar New Port.

Berdasarkan hasil observasi awal yang dilakukan di PT. Pelindo IV Cabang Makassar New Port, penggunaan energi listrik banyak digunakan oleh alat-alat yang bersifat induktif seperti transformator, motor induksi dan peralatan elektronik lainnya yang menggunakan komponen induktor. Salah satu bagian dari Makassar New Port yang dibebani oleh beban induktif adalah Reefer Plug. Reefer Plug dibebani oleh peti kemas pendingin yang menggunakan komponen listrik bersifat induktor yaitu kompresor dan juga dibebani oleh lampu TL untuk sarana penerangan.
Berdasarkan hasil observasi awal pada reefer plug diperoleh data faktor daya 0,72. Penurunan faktor daya akan mengakibatkan rugi-rugi daya dan arus meningkat sehingga dapat merusak sistem kelistrikan karena melebihi batas arus pada kabel penghantar [4].

Menghadapi masalah tersebut Makassar New Port harus menjaga kualitas daya listrik agar sistem operasi yang berlangsung dengan menggunakan peralatan listrik dapat berjalan dengan baik sehingga tidak menimbulkan kerugian terhadap perusahaan. Salah satu cara yang dapat dilakukan untuk mengatasi masalah tersebut yaitu dengan meningkatkan faktor daya.

Faktor daya dapat ditingkatkan dengan meminimalisir daya reaktif yang disuplai oleh PLN. Daya reaktif dapat dihasilkan oleh beban yang bersifat kapasitif. Upaya yang dilakukan oleh pihak Makassar New Port dalam meningkatkan faktor daya yaitu dengan memasang kapasitor bank terhadap beban yang bersifat induktif seperti pada reefer plug. Analisis perubahan faktor daya setelah beban dihubungkan dengan kapasitor bank perlu dilakukan guna mengetahui efektivitas penggunaan kapasitor bank dalam memperbaiki faktor daya.

\section{METODE PENELITIAN}

\section{A. Jenis Penelitian}

Jenis penelitian yang digunakan pada penelitian ini adalah penelitian deskriptif dengan pendekatan kuantitatif.

\section{B. Waktu dan Tempat Penelitian}

Penelitian dilaksanakan di PT. Pelindo IV Cabang Makassar New Port yang terletak di Jl. Sultan Abdullah Raya, Kaluku Bodoa, Kecematan Tallo, Kota Makassar, Sulawesi Selatan pada bulan April sampai bulan Juni 2021.

\section{Alur Penelitian}

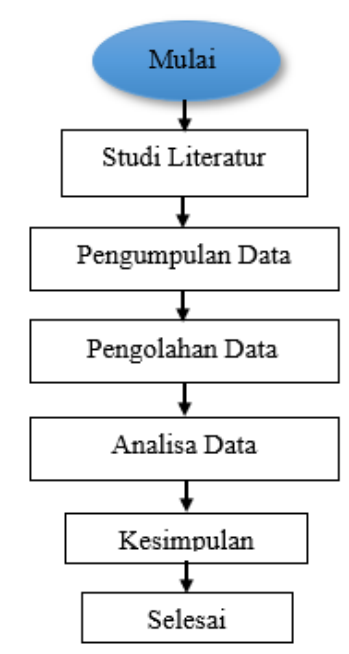

Gambar 1. Alur Penelitian 


\section{HASIL DAN PEMBAHASAN}

\section{A. Hasil Penelitian}

1. Hasil Observasi Faktor Daya Pada Reefer Plug

Berdasarkan hasil observasi, berikut ini adalah deskripsi hasil obeservasi tentang faktor daya pada reefer plug PT. Pelindo IV Cabang Makassar New Port:

TABEL 1. HASIL PENELITIAN BERUPA OBSERVASI FAKTOR DAYA PADA REEFER PLUG

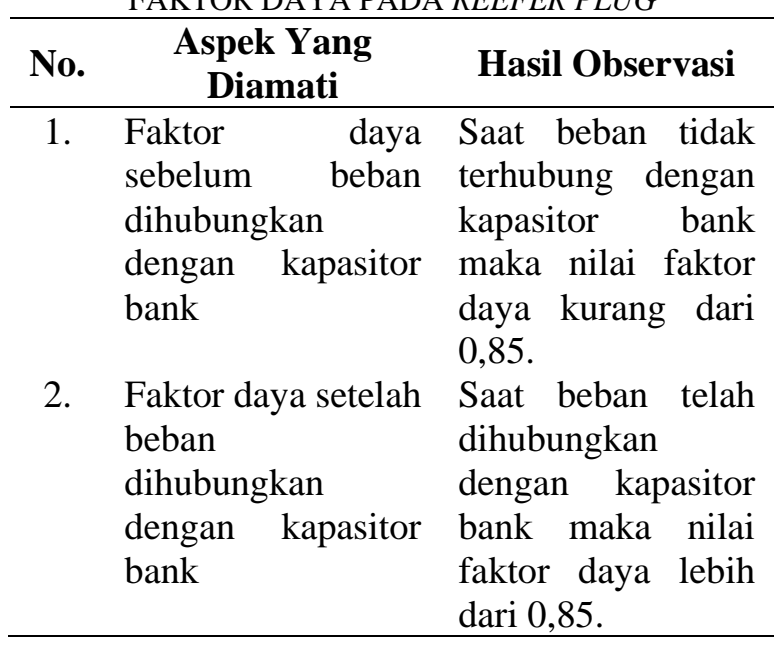

Berdasarkan Tabel 1 di atas, dapat dilihat dari hasil observasi bahwa terdapat pengaruh kapasitor bank terhadap faktor daya pada reefer plug.

2. Data Pengukuran Daya Listrik

Berdasarkan hasil dokumentasi data daya aktif, daya semua, daya reaktif, faktor daya, tegangan dan arus, yang telah dikumpulkan di Makassar New Port, diperoleh data sebagai berikut:

TABEL 2. DATA HASIL PENGUKURAN DAYA AKTIF

\begin{tabular}{|c|c|c|c|c|}
\hline No. & Tanggal & $\begin{array}{c}\text { Daya } \\
\text { Tertinggi } \\
(\mathbf{k W})\end{array}$ & $\begin{array}{c}\text { Daya } \\
\text { Terendah } \\
(\mathbf{k W})\end{array}$ & $\begin{array}{l}\text { Rata- } \\
\text { Rata } \\
\text { (kW) }\end{array}$ \\
\hline 1. & $\begin{array}{l}27 \text { Mei } \\
2021\end{array}$ & 147,7 & 79,2 & 111,5 \\
\hline 2. & $\begin{array}{l}28 \mathrm{Mei} \\
2021\end{array}$ & 36,5 & 32,3 & 34,4 \\
\hline 3. & $\begin{array}{l}31 \mathrm{Mei} \\
2021\end{array}$ & 85,3 & 34,0 & 56,8 \\
\hline 4. & $\begin{array}{l}\text { 4 Juni } \\
2021\end{array}$ & 126,7 & 57,8 & 85,6 \\
\hline 5. & $\begin{array}{l}5 \text { Juni } \\
2021\end{array}$ & 71,5 & 49,1 & 61,0 \\
\hline 6. & $\begin{array}{l}9 \text { Juni } \\
2021\end{array}$ & 100,7 & 92,9 & 97,7 \\
\hline 7. & $\begin{array}{l}10 \text { Juni } \\
2021\end{array}$ & 92,1 & 31,1 & 81,0 \\
\hline \multicolumn{4}{|c|}{ Rata-Rata } & 75,4 \\
\hline
\end{tabular}

Berdasarkan Tabel 2 menunjukkan hasil pengukuran daya aktif dengan rata-rata $75,4 \mathrm{~kW}$. Nilai daya aktif tertinggi yaitu pada tanggal 27 Mei 2021 sebesar $147,7 \mathrm{~kW}$ dan nilai daya aktif terendah yaitu pada tanggal 10 Juni 2021 sebesar $31,1 \mathrm{~kW}$.

\begin{tabular}{|c|c|c|c|c|}
\hline No. & Tanggal & $\begin{array}{c}\text { Daya } \\
\text { Tertinggi } \\
\text { (kVA) }\end{array}$ & $\begin{array}{c}\text { Daya } \\
\text { Terendah } \\
\text { (kVA) }\end{array}$ & $\begin{array}{c}\text { Rata- } \\
\text { Rata } \\
\text { (kVA) }\end{array}$ \\
\hline 1. & $\begin{array}{l}27 \mathrm{Mei} \\
2021\end{array}$ & 205,1 & 106,5 & 151,8 \\
\hline 2. & $\begin{array}{l}28 \mathrm{Mei} \\
2021\end{array}$ & 50,6 & 43,6 & 46,5 \\
\hline 3. & $\begin{array}{l}31 \mathrm{Mei} \\
2021\end{array}$ & 135,2 & 48,8 & 86,4 \\
\hline 4. & $\begin{array}{l}\text { 4 Juni } \\
2021\end{array}$ & 198,0 & 81,9 & 127,6 \\
\hline 5. & $\begin{array}{l}5 \text { Juni } \\
2021\end{array}$ & 109,9 & 66,5 & 87,0 \\
\hline 6. & $\begin{array}{l}9 \text { Juni } \\
2021\end{array}$ & 152,2 & 134,6 & 143,3 \\
\hline 7. & $\begin{array}{l}10 \text { Juni } \\
2021\end{array}$ & 136,4 & 44,3 & 86,6 \\
\hline \multicolumn{4}{|c|}{ Rata-Rata } & 104,1 \\
\hline
\end{tabular}

Berdasarkan Tabel 3 menunjukkan hasil pengukuran daya semu dengan rata-rata $104,1 \mathrm{kVA}$. Nilai daya semu tertinggi yaitu pada tanggal $27 \mathrm{Mei}$ 2021 sebesar 205,1 kVA dan nilai daya semu terendah yaitu pada tanggal 28 Mei 2021 sebesar 43,6 kVA.

TABEL 4. DATA HASIL PENGUKURAN DAYA REAKTIF

\begin{tabular}{|c|c|c|c|c|}
\hline No. & Tanggal & $\begin{array}{c}\text { Daya } \\
\text { Tertinggi } \\
\text { (kVAR) }\end{array}$ & $\begin{array}{c}\text { Daya } \\
\text { Terendah } \\
\text { (kVAR) }\end{array}$ & $\begin{array}{c}\text { Rata- } \\
\text { Rata } \\
\text { (kVAR) }\end{array}$ \\
\hline 1. & $\begin{array}{l}27 \text { Mei } \\
2021\end{array}$ & 142,4 & 70,2 & 103,2 \\
\hline 2. & $\begin{array}{l}28 \mathrm{Mei} \\
2021\end{array}$ & 35,9 & 27,8 & 31,0 \\
\hline 3. & $\begin{array}{l}31 \mathrm{Mei} \\
2021\end{array}$ & 104,9 & 34,8 & 64,9 \\
\hline 4. & $\begin{array}{l}\text { 4 Juni } \\
2021\end{array}$ & 152,1 & 57,6 & 94,5 \\
\hline 5. & $\begin{array}{l}5 \text { Juni } \\
2021\end{array}$ & 83,4 & 44,3 & 61,9 \\
\hline 6. & $\begin{array}{l}\text { 9 Juni } \\
2021\end{array}$ & 114,3 & 96,8 & 104,6 \\
\hline 7. & $\begin{array}{l}10 \text { Juni } \\
2021\end{array}$ & 101,6 & 31,5 & 86,6 \\
\hline \multicolumn{4}{|c|}{ Rata-Rata } & 78,1 \\
\hline
\end{tabular}

Berdasarkan Tabel 4 menunjukkan hasil pengukuran daya reaktif dengan rata-rata $78,1 \mathrm{kVAR}$. Nilai daya reaktif tertinggi yaitu pada tanggal 4 Juni 2021 sebesar 152,1 kVAR dan nilai daya reaktif terendah yaitu pada tanggal 28 Mei 2021 sebesar 27,8 kVAR. 
TABEL 5. HASIL PENGUKURAN FAKTOR DAYA

\begin{tabular}{|c|c|c|c|}
\hline \multirow{2}{*}{ No. } & \multirow{2}{*}{ Tanggal } & \multicolumn{2}{|c|}{$\begin{array}{c}\text { Faktor Daya } \\
(\operatorname{Cos} \varphi)\end{array}$} \\
\hline & & $(\operatorname{Cos} \varphi 1)$ & $(\operatorname{Cos} \varphi 2)$ \\
\hline 1. & 27 Mei 2021 & 0,73 & 0,95 \\
\hline 2. & 28 Mei 2021 & 0,74 & 0,97 \\
\hline 3. & 31 Mei 2021 & 0,66 & 0,96 \\
\hline 4. & 4 Juni 2021 & 0,67 & 0,96 \\
\hline 5. & 5 Juni 2021 & 0,70 & 0,95 \\
\hline 6. & 9 Juni 2021 & 0,68 & 0,94 \\
\hline 7. & 10 Juni 2021 & 0,68 & 0,94 \\
\hline & Rata-Rata & 0,69 & 0,95 \\
\hline
\end{tabular}

Faktor daya atau power factor ( $p f)$ merupakan perbandingan antara daya aktifdan daya semu [5]. Data faktor daya diperoleh dari hasil pengukuran pada reefer plug. Berdasarkan Tabel 5 menunjukkan bahwa nilai rata-rata faktor daya sebelum beban dihubungkan dengan kapasitor bank (Cos $\varphi 1)$ sebesar 0,69 dan nilai rata-rata faktor daya setelah beban dihubungkan dengan kapasitor bank (Cos $\varphi 2)$ sebesar 0,95.

\section{B. Pembahasan}

1. Daya Reaktif Yang Dihasilkan Oleh Kapasitor Bank Dalam Meningkatkan Faktor Daya.

Persamaan yang digunakan untuk menghitung nilai daya reaktif yang dihasilkan dari pemasangan kapasitor bank dalam meningkatkan faktor daya adalah persamaan [6].

$$
Q c=P\left(\operatorname{Tan}_{\varphi 1}-\operatorname{Tan}_{\varphi 2}\right)
$$

Adapun hasil perhitungannya sebagai berikut:

$$
\begin{gathered}
\text { TABEL 6. HASIL PERHITUNGAN DAYA REAKTIF } \\
\text { YANG DIHASILKAN DARI PEMASANGAN } \\
\text { KAPASITOR BANK DALAM MENINGKATKAN } \\
\text { FAKTOR DAYA }
\end{gathered}
$$

\begin{tabular}{|c|c|c|c|c|}
\hline \multirow{2}{*}{ No. } & \multirow{2}{*}{ Tanggal } & \multicolumn{3}{|c|}{ Daya Reaktif (kVAR) } \\
\hline & & $\mathbf{Q}_{1}$ & $\mathbf{Q}_{\mathbf{c}}$ & $\mathbf{Q}_{2}$ \\
\hline 1. & 27 Mei 2021 & 103,2 & 68,0 & 35,2 \\
\hline 2. & 28 Mei 2021 & 31,0 & 22,7 & 8,3 \\
\hline 3. & 31 Mei 2021 & 64,8 & 46,0 & 18,8 \\
\hline 4. & 4 Juni 2021 & 94,5 & 69,3 & 25,2 \\
\hline 5. & 5 Juni 2021 & 61,9 & 41,4 & 20,5 \\
\hline 6. & 9 Juni 2021 & 104,6 & 62,6 & 42,0 \\
\hline 7. & 10 Juni 2021 & 86,6 & 51,8 & 34,8 \\
\hline & Rata-Rata & 78,1 & 51,6 & 26,5 \\
\hline
\end{tabular}

Berdasarkan hasil penelitian yang diperoleh pada Tabel 6 rata-rata nilai daya reaktif pada reefer plug sebelum beban dihubungkan dengan kapasitor bank $\left(\mathrm{Q}_{1}\right)$ yaitu sebesar 78,1 kVAR. Setelah dilakukan pengolahan data diperoleh rata-rata nilai daya reaktif yang dihasilkan dari pemasangan kapasitor bank dalam meningkatkan faktor daya $\left(\mathrm{Q}_{\mathrm{c}}\right)$ yaitu sebesar 51,6 kVAR sehingga rata-rata daya reaktif yang diserap oleh beban $\left(\mathrm{Q}_{2}\right)$ sebesar 26,5 kVAR. Dengan adanya kompensasi yang diberikan oleh kapasitor bank dapat mengurangi penyerapan daya reaktif pada beban sehingga faktor daya akan meningkat yang dapat dibuktikan dengan hasil pengumpulan data yang diperoleh dari hasil pengukuran faktor daya pada panel LVMDP (Low Voltage Main Distribution Panel) reefer plug, adapun bentuk kompensasi daya reaktif menggunakan kapasitor bank untuk meningkatkan faktor daya sebagai berikut:

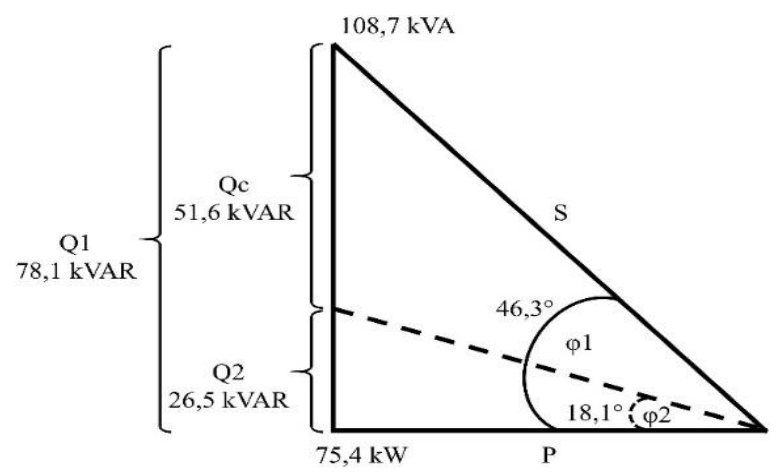

Gambar 2. Perbaikan Faktor Daya Dengan Kompensasi Daya Reaktif

2. Efisiensi Daya

Persamaan yang digunakan untuk menghitung persentase efisiensi daya setelah beban dihubungkan dengan kapasitor bank adalah persamaan [7].

$$
\text { Efisiensi }=\frac{S_{1}-S_{2}}{S_{1}} \times 100 \%
$$

Adapun hasil perhitungannya sebagai berikut:

TABEL 7. PERHITUNGAN PERSENTASE EFISIENSI DAYA

\begin{tabular}{llllll}
\hline \multirow{2}{*}{ No. } & Tanggal & \multicolumn{3}{c}{$\begin{array}{c}\text { Daya Semu } \\
\text { (kVA) }\end{array}$} & \multirow{2}{*}{\begin{tabular}{c} 
Efisiensi \\
\cline { 3 - 5 }
\end{tabular}} \\
\cline { 3 - 5 } & $\mathbf{S}_{\mathbf{1}}$ & $\mathbf{S}_{\mathbf{2}}$ & $\mathbf{S}_{\mathbf{3}}$ & \\
\hline 1. & 27 Mei 2021 & 151,8 & 117,3 & 34,5 & 22,7 \\
2. & 28 Mei 2021 & 46,5 & 35,4 & 11,1 & 23,8 \\
3. & 31 Mei 2021 & 86,4 & 59,1 & 27,3 & 31,5 \\
4. & 4 Juni 2021 & 127,6 & 89,1 & 38,5 & 30,1 \\
5. & 5 Juni 2021 & 87,0 & 64,2 & 22,8 & 26,2 \\
6. & 9 Juni 2021 & 143,3 & 103,9 & 39,4 & 27,4 \\
7. & 10 Juni 2021 & 118,6 & 86,1 & 32,5 & 27,4 \\
\hline \multicolumn{2}{l}{ Rata-Rata } & $\mathbf{1 0 8 , 7}$ & $\mathbf{7 9 , 3}$ & $\mathbf{2 9 , 4}$ & $\mathbf{2 7 , 0 1}$ \\
\hline
\end{tabular}

Berdasarkan hasil penelitian yang diperoleh pada Tabel 7 rata-rata nilai daya semu pada reefer plug sebelum beban dihubungkan dengan kapasitor bank $\left(\mathrm{S}_{1}\right)$ yaitu sebesar 108,7 kVA, kemudian setelah beban 
dihubungkan dengan kapasitor bank rata-rata nilai daya semu $\left(\mathrm{S}_{2}\right)$ yaitu, sebesar 79,3 kVA maka efisiensi penggunaan daya $\left(S_{3}\right)$ sebesar $29,4 \mathrm{kVA}$ dengan rata-rata persentase efisiensi sebesar $27,04 \%$ sehingga dapat mengurangi biaya pemakaian energi listrik sekitar Rp. 31.134, adapun bentuk efisiensi penggunaan daya listrik sebagai berikut:

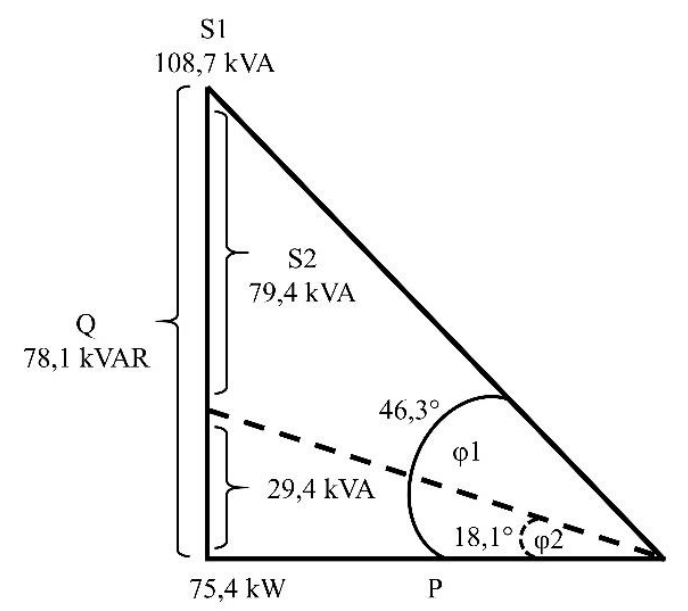

Tabel 8. Efisiensi Penggunaan Daya Listrik

\section{SIMPULAN}

Penelitian ini bertujuan untuk mengetahui efektivitas dari pemasangan kapasitor bank dalam meningkatkan faktor daya pada reefer plug di PT. Pelindo IV cabang Makassar New Port. Berdasarkan data hasil penelitian diperoleh kesimpulan sebagai berikut:

1. Dengan penggunaan kapasitor bank berkapasitas $300 \mathrm{kVAR}$ rata-rata daya reaktif yang dihasilkan sebesar 51,6 kVAR, dimana rata-rata daya reaktif sebelum beban dihubungkan dengan kapasitor bank sebesar 78,1 kVAR sehingga rata-rata daya reaktif yang diserap oleh beban sebesar 26,5 kVAR.

2. Rata-rata daya semu sebelum beban dihubungkan dengan kapasitor bank sebesar 108,7 kVA. Setelah beban dihubungkan dengan kapasitor bank rata-rata daya semu berkurang menjadi 79,3 kVA, sehingga persentase efisiensi penggunaan kapasitor bank sebesar 27,04\%.

\section{DAFTAR PUSTAKA}

[1] Erik Pranata Saragih, "Analisa Pengaruh Pemasangan Kapasitor Bank Terhadap Beban Listrik Di Alfamart," Universitas Muhammadiyah Sumatera Utara, Medan, 2019. [Online]. Available: http://repository.umsu.ac.id/handle/1234567 $89 / 1449$
[2] R. R. FAHLEVI, "Pengaruh Pemasangan Kapasitor Bankterhadap Faktor Daya Pada Auxiliary Equipment Di Pt Semen Baturaja Site Palembang," Politeknik Negeri Sriwijaya, 2017.

[3] N. Putra and A. Premadi, "Evaluasi Jatuh Tegangan Sistem Kelistrikan PLTMH Hululayang 13 KW," Jurnal Teknik Elektro, vol. 4, no. 2, 2015.

[4] A. S. Salsabila, "Analisis Pengaruh Penggunaan Kapasitor Untuk Perbaikan Faktor Daya Pada Sistem Distribusi $20 \mathrm{Kv}$ (Studi Kasus: Pt. Pln (Persero) Ulp Leles)," Universitas Pendidikan Indonesia, 2021.

[5] M. Ramdhani, "Rangkaian Listrik (Revisi)," Laboratorium Sistem Elektronika Jurusan Teknik Elektro. Sekolah Tinggi Teknologi Telkom Bandung, 2005.

[6] A. K. Al Bahar, "Analisa Pengaruh Kapasitor Bank Terhadap Faktor Daya Gedung TI BRI Ragunan," Jurnal Ilmiah Elektrokrisna, vol. 6, no. 1, 2017.

[7] S. Noor and N. Saputera, "Efisiensi Pemakaian Daya Listrik Menggunakan Kapasitor Bank," Poros Teknik, vol. 6, no. 2, pp. 73-79, 2014. 